\title{
Os usos sociais do conceito de cultura: a legitimação de patrimônios por representações
}

\author{
The social uses of the concept of culture: \\ the legitimation of heritages by representations
}

\author{
Willian Eduardo Righini de Souza ${ }^{1}$, Giulia Crippa ${ }^{2}$
}

\section{RESUMO}

O objetivo deste artigo é apresentar e discutir um estudo de caso sobre como as noções de cultura utilizadas pelos moradores de uma pequena cidade do interior do Estado de São Paulo, Santa Rosa de Viterbo, influenciam e participam da formação e legitimação de patrimônios culturais locais. Observando a polissemia desta palavra, realizaram-se entrevistas para verificar as representações sociais de determinado grupo de habitantes sobre o que é considerado cultura e pode ser entendido como patrimônio nesta cidade. A partir de dois exemplos, que são a Banda Sinfônica e a Semana Universitária, discutimos como uma mesma definição de cultura pode produzir efeitos diferentes dependendo dos sujeitos sociais e dos ambientes nos quais ela é utilizada.

Palavras-chave: Cultura. Patrimônio cultural. Memória social.

\section{ABSTRACT}

The aim of this paper is to present and discuss a case study on how the notions of culture used by residents of a small town of São Paulo State, Santa Rosa de Viterbo, influence and participate of the formation and legitimation of local cultural heritage. Noting the polysemy of this word, interviews were conducted to verify the social representations of a determined group of inhabitants about what is considered culture and can be understood as heritage in this city. From two examples, which are the Symphonic Band and the University Week, we discuss how the same definition of culture can produce different effects depending on the social subjects and the environments in which it is used.

Keywords: Culture. Cultural heritage. Social memory.

\footnotetext{
${ }^{1}$ Graduado em Ciências da Informação e Documentação pela Faculdade de Filosofia, Ciências e Letras de Ribeirão Preto - USP. Mestrando em Ciência da Informação pela Escola de Comunicação e Artes - USP.

${ }^{2}$ Doutora em História Social pela Faculdade de Filosofia, Letras e Ciências Humanas - USP. Professora Doutora do curso de Ciências da Informação e Documentação da Faculdade de Filosofia, Ciências e Letras de Ribeirão Preto e do programa de pós-graduação em Ciência da Informação da Escola de Comunicação e Artes - USP.
}

Esta obra foi licenciada com uma Licença Creative Commons - Atribuição 3.0 Não Adaptada. 


\title{
1 INTRODUÇÃO
}

Como identificar um patrimônio cultural? Por que alguns bens são reconhecidos como símbolos de uma cidade e outros não? Como são justificados e legitimados os seus valores? Muitas vezes, a concepção de que sua relevância é evidente e inerente à sua materialidade acaba por ocultar o processo que explica sua seleção e as percepções e representações sociais.

No Brasil, durante praticamente todo o século $X X$, a determinação do que era ou não patrimônio nacional ficou a cargo de especialistas e técnicos do Instituto do Patrimônio Histórico e Artístico nacional (IPHAN) que, primeiro, verificavam quais eram os valores históricos e artísticos/ estéticos de uma obra para, depois, definirem se esta deveria ser vista como memorável para a história da nação. O resultado foi a preservação maciça de obras de origem portuguesa e religiosa católica dos séculos XVI, XVII e XVIII (FONSECA, 2005).

Uma mudança de perspectiva iniciou-se em 1975 com a criação do Centro Nacional de Referência Cultural ${ }^{3}$ (CNRC) e a presidência do IPHAN por Aloísio Magalhães entre 1978 e 1982, que ao questionarem as políticas até então vigentes ampliaram as noções de bem e patrimônio cultural, culminando em uma nova definição na Constituição Federal de 1988, marcada pelo reconhecimento dos diferentes grupos que formam a sociedade brasileira e suas práticas:

\begin{abstract}
Art. 216. Constituem patrimônio cultural brasileiro os bens de natureza material e imaterial, tomados individualmente ou em conjunto, portadores de referência à identidade, à ação, à memória dos diferentes grupos formadores da sociedade brasileira (...) (BRASIL, 1988).
\end{abstract}

A partir de então, cada vez mais, os responsáveis por essas políticas têm considerado, além das características arquitetônicas, estilísticas, artísticas etc., o olhar da população sobre um bem, possibilitando que entre os patrimônios culturais se incluam desde pinturas corporais a pratos típicos.

De modo geral, essa transformação reflete os diferentes usos da ideia de cultura pelas instituições do setor. Antes da criação do CNRC e a presidência de Aloísio Magalhães, as obras tombadas se referiam principalmente à cultura erudita e

\footnotetext{
${ }^{3}$ O CNRC desenvolveu projetos culturais em áreas que, na época, eram pouco exploradas em âmbito federal: artesanato; levantamentos socioculturais; história da tecnologia e da ciência no Brasil e levantamento de documentação sobre o Brasil.

Cad. de Pesq. Interdisc. em Ci-s. Hum-s., Florianópolis, v.12, n.101, p.199-218, ago/dez 2011
} 
dominante, a atividades artísticas e intelectuais tradicionais praticadas por apenas uma parcela da população. Com as discussões das décadas de 1970-80, a noção de cultura assumiu uma perspectiva mais antropológica, de "modo de vida global", e, ao contrário de tentar identificar uma cultura nacional, os trabalhos se dirigiram para a valorização da nossa diversidade e heterogeneidade.

Como observa Chartier (2009, p. 34), esta dualidade do conceito de cultura pode ser esquematicamente dividida em duas linhas de significado:

a que designa as obras e os gestos que, em uma sociedade dada, se subtraem às urgências do cotidiano e se submetem a um juízo estético ou intelectual e a que aponta as práticas comuns através das quais uma sociedade ou um indivíduo vivem e refletem sobre sua relação com o mundo, com os outros ou com eles mesmos.

O risco, para DaMatta, é que a visão de cultura como um conjunto de atividades artísticas e intelectuais permite que ela seja usada como sinônimo de "sofisticação, de sabedoria, de educação no sentido restrito do termo" (DAMATTA, 1981, p.1), alimentando a perspectiva de que algumas pessoas têm cultura e outras não, de que algumas sociedades são avançadas e outras atrasadas. Neste sentido, a palavra cultura é utilizada para classificar e hierarquizar pessoas, grupos sociais e nações, tornando-se um instrumento de discriminação e exclusão.

Recorrendo aos referenciais teóricos da Antropologia e Sociologia, o autor defende a concepção inclusiva, na qual todos os homens, sociedades e países possuem cultura, e que, apesar de singulares, não se encontram em diferentes estágios de desenvolvimento. De forma sucinta, cultura seria "um código através do qual as pessoas de um dado grupo pensam, classificam, estudam e modificam o mundo e a si mesmas" (DAMATTA, 1981, p.2).

Já para García Canclini (2007, p.41), a clássica definição antropológica de cultura como a "totalidade da vida social" apenas separa a cultura da natureza e não da sociedade, tornando-a um conceito muito amplo, que engloba quase tudo. Assim, o autor sugere uma definição mais operacional e restrita, de cultura como os "processos sociais de produção, circulação e consumo da significação na vida social" (GARCÍA CANCLINI, 2007, p. 45). Nesta abordagem, sua visão se aproxima do conceito de Geertz (2008), que pensa a cultura a partir de uma interpretação semiótica. Para este último, a cultura pode ser definida como "um sistema de concepções herdadas expressas em formas simbólicas por meio das quais os 
homens comunicam, perpetuam e desenvolvem seu conhecimento e suas atividades em relação à vida" (GEERTZ, 2008, p. 66).

Como observou Laraia (2001), desde a primeira formulação conceitual de cultura, em 1871, sob o ponto de vista antropológico na obra Primitive culture de Edward Tylor, compreendendo-a como "todo complexo que inclui conhecimentos, crenças, arte, moral, leis, costumes ou qualquer outra capacidade ou hábitos adquiridos pelo homem como membro de uma sociedade" (TYLOR, 1871 apud LARAIA, 2001, p. 25), surgiram tantas definições de cultura que, ao invés de permitir um consenso sobre o seu conceito, estabeleceram mais confusões e divergências teóricas, levando pesquisadores como Geertz, acima citado, a defender uma diminuição de sua amplitude conceitual para permitir um uso mais controlado (LARAIA, 2001, p. 27).

De qualquer modo, Williams (2007, p. 121) reconhece que a noção mais difundida de cultura é a de "música, literatura, pintura, escultura, teatro e cinema", sendo inclusive a perspectiva adotada pelos Ministérios da Cultura, e, ao contrário de uma posição pessimista, acredita que todo o movimento de vê-la como um sistema de significações gerais também ampliou a noção de "atividades artísticas e intelectuais", atenuando a oposição entre as duas concepções aqui tratadas. Ela não seria apenas as

artes e formas de produção intelectual tradicionais, mas também todas as 'práticas significativas' - desde a linguagem, passando pela arte e filosofia, até o jornalismo, moda e publicidade - que agora constituem esse campo complexo e necessariamente extenso (WILLIAMS, 2008, p 13) ${ }^{4}$.

Porém, se a sociedade não vê a cultura como uma "maneira de viver total", como diz DaMatta, mas como um conjunto determinado de atividades, diferente do que defende García Canclini, o que é entendido por patrimônio quando adjetivado de cultural? Como a noção de cultura influencia na leitura e valorização de patrimônios?

O intuito deste artigo é apresentar e discutir um estudo de caso que mostra como as noções de cultura utilizadas pelos moradores de uma pequena cidade do interior do Estado de São Paulo, Santa Rosa de Viterbo ${ }^{5}$, são decisivas para a

\footnotetext{
${ }^{4}$ Williams (2007, p.121) ainda analisa mais duas concepções de cultura, na qual o segundo significado pode ser considerado um dos resultados do contato com atividades artísticas e intelectuais: 1) Cultura como cultivo da terra, processo físico, permitindo, posteriormente, a ideia de cultivo da mente, tornando-se culto e 2) Cultura como desenvolvimento intelectual, espiritual e estético.

${ }^{5}$ Santa Rosa de Viterbo está a trezentos e dez quilômetros da capital do Estado e possui 23.871 habitantes segundo o Censo 2010 realizado pelo Instituto Brasileiro de Geografia e Estatística (IBGE). Cad. de Pesq. Interdisc. em Ci-s. Hum-s., Florianópolis, v.12, n.101, p.199-218, ago/dez 2011
} 
valorização de determinados bens e a exclusão de outros entre aqueles que são considerados patrimônios culturais.

Desde 2006, realizamos pesquisas que abordam o discurso patrimonial na região de Ribeirão Preto, onde Santa Rosa se encontra, e a partir da constatação, seja em contato com os responsáveis pelas políticas culturais da cidade como pela consulta a documentos locais, de que o município não possuía um programa em execução ou já executado para a identificação, preservação e promoção dos seus patrimônios, entendemos que ele apresentava condições propícias para a aplicação de entrevistas que vislumbravam analisar os bens culturais que são vistos como símbolos de identidade, memória e cultura pelos seus moradores e não, necessariamente, pelos administradores locais, o que seria muito mais difícil se o município já tivesse estabelecido e promovido ações oficiais e simbólicas que determinassem, pelo poder público, quais eram os seus patrimônios.

Não pretendemos produzir uma discussão que enalteça uma definição de cultura, mas mostrar algumas consequências dos seus diferentes usos. Ao considerarmos que os patrimônios são discursivamente constituídos, entre os nossos objetivos está o de analisar esses discursos para compreender a classificação, pelos moradores, de determinados bens como patrimônios culturais (GONÇALVES, 2007), que, neste artigo, serão a Banda Sinfônica de Santa Rosa de Viterbo e a Semana Universitária Santa-rosense.

Para tanto, aplicamos entrevistas semiestruturadas, em um grupo selecionado de habitantes, que abordavam desde os lugares que mais gostavam na cidade à avaliação que faziam da política cultural da prefeitura. Como embasamento metodológico, utilizamos referenciais da história oral (ROUVEROL, 2003; MEIHY; HOLANDA, 2007; PORTELLI; 1996) que privilegiam a interação do pesquisador com o colaborador entrevistado. Assim sendo, após entrarmos em contato com alguns santa-rosenses propondo-Ihes a entrevista, buscamos um contato contínuo que permitisse aos mesmos acompanhar o andamento da discussão/pesquisa, autorizando ou mesmo estimulando a sua participação, por meio da revisão das transcrições e envio de novas informações, nas análises realizadas. Com este propósito, conseguimos o depoimento de um grupo pequeno, mas diverso de moradores em idade, ocupação e influência na cidade: dos treze participantes, um nasceu na década de 1940, três na de 1950, três na de 1960, três na de 1970 e três 
na de 1980. Em relação às ocupações, conversamos com estudantes universitários, professores, funcionários públicos, escritores, memorialistas locais, jornalistas, administradores da cultura e educação, entre outros, com diferentes graus de aproximação com o poder local. Além disso, ao longo da pesquisa de campo, mantivemos contato com demais santa-rosenses que nos forneciam informações e expressavam suas opiniões sobre o tema analisado, consultamos documentos públicos e observamos o cotidiano da população. Portanto, os resultados aqui divulgados não se resumem aos participantes citados nominalmente neste trabalho, mas estão relacionados a todo um quadro de investigação que elaboramos durante este percurso.

Ao realizarmos entrevistas com habitantes que acompanham/ já participaram dos eventos culturais do município ou estão relacionados à sua administração, encontramos diferentes concepções sobre o que é cultura. Em alguns casos, aproximam-se da ideia de modo de vida, pois consideram as diversas formas de expressão do social, suas manifestações. Entretanto, a visão dominante de cultura é a de "atividades artísticas e intelectuais" e seus produtos, que além de conhecimento/ tornar-se culto permitiria a inclusão social e, consequentemente, uma melhor qualidade de vida.

Desta forma, esperamos mostrar como os diferentes usos deste conceito podem prejudicar ou auxiliar na preservação e divulgação de bens considerados identitários e memoráveis pela sociedade, desmitificando a ideia de que uma concepção de cultura é melhor do que a outra, mas que elas dependem dos contextos sociais/ ambientes nos quais estão inseridas.

\section{A BANDA SINFÔNICA}

Antes mesmo de 1910, ano no qual Santa Rosa de Viterbo deixou de ser distrito e tornou-se cidade, verifica-se, em seu território, a presença de bandas de música. Inicialmente promovidas pelos imigrantes italianos que buscavam trabalho na região na passagem do século $X I X$ para $o X X$, elas se popularizaram $e$ permaneceram presentes no município ao longo de todo o século passado, como 
demonstram fotografias e documentos que citam as já extintas Bandas Dumont, Giuseppe Verdi e Santa Cecília. Cabe explicar que muitas dessas bandas não diferiam das anteriores, pois permaneciam com praticamente os mesmos integrantes e maestro, só modificando o nome. A primeira foi a Dumont, na primeira década do século, depois a Giuseppe Verdi na década seguinte, e assim por diante até a mais duradoura antes do período presente, a Santa Cecília, que existiu do decênio de 1940 ao começo do de 1980. Em continuidade a esta prática, no ano de 1985, a antiga estação de trem da cidade foi restaurada e transformada pela prefeitura em um espaço, denominado Estação da Cultura, para abrigar uma nova banda sinfônica, a Banda Sinfônica de Santa Rosa de Viterbo, e ministrar aulas gratuitas de música para mais de trezentas crianças e adolescentes santa-rosenses. Assim sendo, a banda que discutiremos neste artigo é a atual banda sinfônica, em atividade desde esse ano (1985).

Para grande parte dos moradores, ela sintetiza o que compreendem por cultura, no sentido de "atividades artísticas e intelectuais", tornando-se um símbolo que merece ser reconhecido e valorizado na cidade. Além disso, por ter sido institucionalizada, possuir um espaço próprio e desenvolver atividades de inclusão "cultural", ela é vista como um modelo que de sucesso e que deve ser copiado.

\begin{abstract}
"Uma pessoa sem cultura é, nos seus vários sentidos, uma pessoa que praticamente não vive. A cultura faz parte do nosso dia-a-dia, é através dela que a gente se reconhece, é através dela que a gente vive, então é essencial! A pessoa que difunde sua cultura, que reconhece e que sabe valorizar, é mais fácil de ser reconhecida perante o global. E para Santa Rosa, está em crescimento e para melhor, porque quando fala Santa Rosa de Viterbo, todo mundo diz ' - Ah, é a cidade que tem a Banda Sinfônica', porque ela é reconhecida em toda a região. É um exemplo assim forte, porque é mais atuante, mas poderia ser reconhecida pelo teatro também, basta o incentivo" (Suzana, 21 anos).
\end{abstract}

Através da banda, alguns habitantes desenvolvem, discursivamente, uma identidade cultural santa-rosense nos moldes teóricos apresentados por Cuche (1999). Comparando a cidade com localidades vizinhas ou mesmo apresentando-a a um visitante/ desconhecido, referem-se à banda como um diferencial do município, algo que remete às suas origens. Dessa maneira, ao acreditarem que identificar a cidade como "aquela que tem a banda sinfônica" é o mesmo que "aquela que tem cultura", aceitam e reproduzem esta representação como uma identidade positiva, uma alteridade desejada. 
Por materializar a noção de cultura, ela dificilmente surge como ponto de conflito ou é questionada em sua importância. Primeiro, porque, na conjuntura de Santa Rosa, sem teatro, museu e demais instituições culturais, uma banda sinfônica é o que mais se aproxima de uma ideia de "alta" cultura, favorecendo a opinião de que ela deve ser apreciada como demonstração de bom gosto e distinção. Até mesmo uma pessoa que nunca ouviu a banda e não conhece seus projetos é capaz de referenciá-la como uma iniciativa positiva a partir da concepção de que uma banda sinfônica, assim como uma exposição de obras de arte ou a leitura de um livro, permite "adquirir" cultura. Segundo, porque ao ser caracterizada pela administração local em veículos publicitários (pôsteres, outdoors) como a "sinfonia do rio Pardo", em referência ao rio que atravessa o município, ela não é apresentada apenas como uma banda de música, mas como um símbolo santa-rosense, única pela sua localização. Deste modo, uma crítica à banda é também à cidade, que nesta definição tornam-se indissociáveis.

\begin{abstract}
"Não posso deixar de ressaltar que temos em nossa cidade a Banda Sinfônica, que atualmente é destaque e realiza apresentações em várias cidades da região. Isso me deixa extremamente orgulhoso" (Valter, 40 anos).

"Nós temos uma banda fantástica que é uma referência nacional. A banda de Santa Rosa é uma das três melhores do Brasil. (...) A banda não tem preço. Santa Rosa hoje tem uma escola de música que vem de vinte anos. Todos os prefeitos merecem parabéns. Não só quem criou, mas os que mantiveram funcionando no mesmo nível. Santa Rosa tem seiscentos alunos de música. Tem três bandas: a banda filarmônica, a juvenil e a iniciante. $E$ tem mais uma garotada que está aprendendo música, que vai se renovando" (André, 42 anos).
\end{abstract}

Ao vincular a banda ao rio Pardo, reforça-se a concepção de que a música é uma aptidão natural dos santa-rosenses, observável desde a fundação da cidade. Como bandas já existiam no município antes mesmo de 1910, como observamos em fotografias de $1901^{6}$ da Banda Dumont, a Sinfônica de Santa Rosa, vista como descendente das demais, adquiriu o status de tradição, que, pelo discurso de repetição e continuidade em relação ao passado (HOBSBAWN, RANGER, 2008), tornou-se "historicamente coerente" (GONÇALVES, 2002, p. 116). Em determinadas condições, considerando uma interpretação abrangente, poderíamos inclusive entender que alguns moradores acreditam que esta suposta aptidão não seja

\footnotetext{
${ }^{6}$ Segundo Romeu José Antunes, jornalista e memorialista local, apesar de existir referências que citam a existência da Banda Dumont já em 1901, o primeiro registro confiável sobre as suas atividades refere-se ao ano de 1904.
}

Cad. de Pesq. Interdisc. em Ci-s. Hum-s., Florianópolis, v.12, n.101, p.199-218, ago/dez 2011 
somente fruto de um processo cultural, mas também herdada biologicamente, como discute Laraia (2001) ao apresentar a ideia de determinismo biológico em sua obra.

\begin{abstract}
"Em cidade pequena, as opções de cultura, de aprendizado de arte, são muito poucas. Na grande maioria das cidades do interior, a única opção de aprendizado de música acaba sendo a escolinha da banda; não existe outra opção. Aqui em Santa Rosa, nós instituímos isso, criou-se um espaço, uma metodologia, as bandas de acesso, então aí abriu espaço para as pessoas. (...) A gente dá sequência a uma tradição e não deixou ela extinguir. As pessoas sentem necessidade de aprender música. Faz parte da vida das pessoas, não tem como separar. (...) uma cidade que tem tradição de bandas como a nossa, não pode querer mudar para uma área que não existe, que nunca teve experiência. Pode até começar com outros projetos, mas tem que apoiar o que é natural da cidade" (Maurílio, 51 anos).
\end{abstract}

Portanto, quando a antiga estação ferroviária local da Cia. Mogiana ${ }^{7}$ se transformou na Estação da Cultura para atender as necessidades da Banda Sinfônica, os discursos sobre a música em Santa Rosa, definitivamente, se legitimaram. Com o apoio da prefeitura, o reconhecimento público e o espaço próprio, foi possível desenvolver uma política administrativa e programas sociais independentemente das mudanças de prefeitos e diretores culturais. A banda assumiu o papel de principal bem cultural local, o parâmetro para o desenvolvimento de outras iniciativas, o que fica claro ao verificarmos o papel exercido pelo seu maestro, Maurílio de Oliveira Júnior, que além de dirigir a banda, é um dos principais responsáveis por praticamente todos os eventos que a cidade produz, desde o Carnaval de rua ao Encontro de Folia de Reis.

"Eu acho que (a cidade) é ainda pobre em matéria de programas culturais. O que salva muito é a nossa Estação da Cultura, que foi montada na época do seu Nagib (ex-prefeito). Essas coisas que foram montadas com base, com muito apoio político e conseguiu um estágio, um avanço no programa, ficaram depois que o seu Nagib deixou a prefeitura. (...) Isso é o resultado de um trabalho bem feito que os prefeitos que vieram não puderam destruir, porque ele tinha uma base muito sólida, que foi a formação dos alunos, uma banda já bem montada. Quem que ia por a mão?" (Badra, 69 anos).

A estabilidade da banda não se restringe somente ao apoio político e valorização social, mas à possibilidade de receber financiamentos privados e governamentais para a sua manutenção. Pela Lei Rouanet e pelos recursos de empresas da região já foram comprados instrumentos musicais, a Estação da Cultura foi reformada e um CD da banda foi gravado (SANTA ROSA DE VITERBO, c2009). Nesse momento, a construção de uma imagem que a vincula à cidade e região favorece os investimentos de empresas locais, e o seu projeto social, de

\footnotetext{
${ }^{7}$ A Companhia Mogiana de Estradas de Ferro foi uma companhia ferroviária brasileira criada em 1872.
}

Cad. de Pesq. Interdisc. em Ci-s. Hum-s., Florianópolis, v.12, n.101, p.199-218, ago/dez 2011 
oferecer aulas de música para mais de trezentas crianças e jovens, formar professores e fazer apresentações gratuitamente, justifica sua relevância também para o poder público.

Questionada sobre o sucesso da banda em relação a outros projetos na cidade, Suzana, uma das entrevistadas, aponta os investimentos realizados como uma das explicações:

"Ela recebe muito patrocínio de empresas privadas. Então, tendo dinheiro, que é uma base importante, acaba sendo mais reconhecida. (...) se (você) vê todo mundo uniformizado, bonito, todos os instrumentos novos, um maestro competente, músicos com vontade de tocar e tal, (ela) acaba sendo reconhecida. Imagina se não tivesse incentivo; acho que não seria tão reconhecida".

Possuir um espaço para receber alunos, se preparar e fazer apresentações é um dos aspectos em que a banda mais se sobressai em relação às outras atividades na cidade. Segundo os participantes da pesquisa, uma das principais deficiências de Santa Rosa é não ter espaços para o desenvolvimento de atividades culturais, sendo a Estação da Cultura o contraponto, o referencial. Observam, inclusive, atividades emergentes, como a dança, mas reconhecem que elas não se desenvolvem porque não têm condições de se organizarem. Por esses motivos, o próprio maestro da banda, que também participa da administração do setor cultural no município, tem buscado recursos financeiros para a construção de diversos espaços culturais, permitindo apresentações teatrais, musicais, entre outros.

Esta atenção é, provavelmente, o maior benefício de um bem ser definido nos discursos e ações oficiais como uma expressão cultural local, pois mesmo alguns outros lugares também serem reconhecidos e estimados pela população, não despertam igual interesse dos governantes e setor privado pela sua preservação e manutenção, devido a não atribuição de valores, a nível institucional, que permitem identificá-los como símbolos da cidade.

\footnotetext{
"Existem, por exemplo, áreas como a dança, pintura, artesanato, teatro, uma série de atividades culturais que não se desenvolvem porque não tem espaço físico. Nós temos aqui na cidade uma série de pessoas que gostam de dança, mas vai dançar onde? Onde vai implantar esse curso? Não tem lugar. (...) Como vai desenvolver o teatro se não tem o espaço para as pessoas se apresentarem ou mesmo praticarem? Como vai desenvolver a dança se não tem a sala apropriada?" (Maurílio, 51 anos).

"Em relação à dança, posso dizer que temos vários lideres, pessoas que se forem incentivadas e se proporcionarmos condições vão trazer desenvolvimento nessa área. (...) Não adianta falar: ' - Ah, tendo uma árvore, debaixo dela eu consigo fazer tudo'. Isso é uma filosofia bonita, mas que não é fato" (Valter, 40 anos).
} 
Em situação oposta, verifica-se que a banda adquiriu predicados que permitem e explicam sua citação constante e valorização pela população, poder público e setor privado santa-rosense. Independentemente do fato de ser ou não uma tradição inventada, do seu sucesso ter sido traçado como natural ou uma aptidão local nata, muitas das representações positivas da cidade fazem referência à banda como símbolo de cultura, entendida como um conjunto de atividades artísticas e intelectuais. Um ponto positivo é que, desta forma, ela consegue manter suas atividades e projetos sociais, garantindo que crianças e jovens recebam uma formação musical, mesmo em períodos de mudanças políticas.

Sustentada pelas ideias de tradição e cultura, a banda tornou-se praticamente um consenso e questioná-la exigiria revisar o que é considerado a identidade local, manifestação típica: a música. Como aborda Fonseca (2005), essas políticas patrimoniais, mesmo quando não assumem esse nome, atingem um grau de eficiência simbólica tão alto que raramente ocorrem contestações pela população quanto ao valor de um bem. Deste modo, a partir do momento em que essas representações existem, elas produzem efeitos que não podem ser ignorados somente porque seguiu um percurso imaginado. Aquilo que pode ser chamado de invenção foi o que, na realidade, permitiu que a banda adquirisse todo o reconhecimento hoje existente. A banda, assim como qualquer outro patrimônio, é um meio, ideológico e político, pelo qual se dá forma e conteúdo a abstrações como "identidade", "memória" e "nação" (ARANTES, 1984, 8). Portanto, além de referências a períodos e fatos históricos para legitimar um bem como patrimônio cultural, é necessário compreender os valores atribuídos pela sociedade através dos seus usos. Segundo Durham (1984, p. 30-31),

\footnotetext{
devemos tentar definir o patrimônio em função do significado que possui para a população, reconhecendo que o elemento básico na percepção do significado de um bem cultural reside no uso que dele é feito pela sociedade.
}

Assim sendo, compreende-se o porquê da banda ser considerada um dos principais patrimônios santa-rosense, pois além de sua já reconhecida relevância para a história e cultura da cidade também se instituiu como discurso e narrativa, uma alegoria da identidade local e daquilo que a população entende por cultura. Ainda, ter como sede uma estação ferroviária desativada, vista como lugar histórico, fortalece a relação da banda com o próprio desenvolvimento do município, como se 
seus trilhos ligassem o passado, o presente e o futuro.Contudo, a Banda Sinfônica poderia ser ainda mais valorizada se seus integrantes e o público também a vissem como uma atividade de lazer ${ }^{8}$, uma ocasião para ouvir música e preencher o tempo livre, e não somente uma oportunidade para "adquirir" e "mostrar" cultura, mesmo que sejam estas as características que autorizam sua visualização como patrimônio cultural.

\section{A SEMANA UNIVERSITÁRIA}

Segundo podemos observar, principalmente entre os jovens, possuir lugares para sair, se divertir e entreter é um dos principais desejos dos santa-rosenses ${ }^{9}$.

É comum a reclamação de que a cidade não oferece praticamente nenhuma atividade para preencher o tempo livre e que são obrigados a frequentar sempre os mesmos lugares por falta de opções:

"Não tem muita opção de lazer. A maioria das pessoas jovens acha ruim. (As pessoas falam) que não tem nada para se fazer, que são sempre os mesmos lugares pra sair. É que os únicos lugares que tem pra sair são o (bar) Chiqueirinho, a praça e o Grêmio (Recreativo)" (Paula, 25 anos).

"É muito bom aqui, mas não tem quase nada. (...) Se você quiser ter um grupinho de pessoas que toque música, fale sobre música, vai ser muito difícil; aqui é tudo muito restrito" (Mateus, 29 anos).

Nesta situação, a Semana Universitária Santa-rosense (SUSA) aparece como a capacidade do município em oferecer lazer para os seus habitantes e, como a Banda Sinfônica, um modelo a ser seguido pelas próximas gerações. Dessa forma, enquanto a banda, de modo geral e dominante, simboliza cultura, a SUSA se sobressai como um modelo de lazer ${ }^{10}$.

\footnotetext{
${ }^{8}$ É provável que muitos dos seus integrantes considerem a banda uma atividade de lazer, mas, de modo geral, esta concepção não surgiu entre os participantes desta pesquisa.

${ }^{9}$ Para Dumazedier $(2001$, p. 34), o lazer "é um conjunto de ocupações às quais o indivíduo pode entregar-se de livre vontade, seja para repousar, seja para divertir-se, recrear-se e entreter-se ou, ainda para desenvolver sua informação ou formação desinteressada, sua participação social voluntária ou sua livre capacidade criadora após livrar-se ou desembaraçar-se das obrigações profissionais, familiares e sociais".

${ }^{10}$ Segundo Aquino e Martins (2007), "ócio" é uma palavra mais abrangente que "lazer", pois enquanto o segundo pressuporia apenas atividades de descanso, diversão e desenvolvimento que são realizadas entre os períodos de trabalho, o primeiro incluiria tudo o que é realizado nas horas vagas relacionado ao "prazer da experiência", sem outro fim que não seja o enriquecimento da natureza humana. No entanto, preferimos utilizar o termo "lazer" em uma acepção ampla, pois foi com esta expressão que os participantes da pesquisa demonstraram sua preocupação inclusive com aquilo que Cad. de Pesq. Interdisc. em Ci-s. Hum-s., Florianópolis, v.12, n.101, p.199-218, ago/dez 2011
} 
Ao ser criada em 1970 por um grupo de estudantes universitários santarosenses que passavam as férias do mês de julho na cidade, o seu objetivo era oferecer uma semana com diferentes atividades culturais, esportivas e de lazer principalmente para a população jovem. Sob a responsabilidade de uma comissão de universitários, programavam-se, a cada ano, apresentações musicais, gincanas, palestras, oficinas e desfiles de beleza.

Considerando que a cidade, formada majoritariamente por famílias descendentes de imigrantes e trabalhadores rurais de baixa renda, não possuía instituições de ensino superior e que cursar uma universidade era algo restrito a apenas uma pequena parcela da população, a SUSA, nos seus primeiros anos, não oferecia o mesmo apelo popular que viria a adquirir posteriormente. Segundo Boniperti, um dos entrevistados, quando ela surgiu, "era altamente elitista", ao ponto de seus pais nunca sequer terem ouvido falar da semana, até que ele, depois de formado, começasse a frequentá-la nas décadas seguintes. Por outro lado, nesse ambiente ainda fundador, foram possíveis discussões sobre a situação política dos anos 70, o movimento estudantil e o futuro do país.

Com as transformações sociais, a SUSA também foi se modificando e perdeu o papel mobilizador dos anos iniciais. Atualmente, ela continua sendo realizada todo ano e o seu sucesso e importância para os jovens da cidade ainda é lembrado, mas agora porque acreditam que ela é uma opção de lazer, em uma perspectiva dissociada da ideia de cultura com a qual estava fortemente relacionada há quarenta anos.

\begin{abstract}
"A SUSA está perdendo a origem dela. Quando eu vim para cá com as crianças, quando ela começou, tinha um grupo de músicos que saíam na rua dançando; era tudo muito simples. Aí tinha gincana, a população participava mesmo. As crianças maiores participavam de gincana, teatro, competições. Agora está diferente. Tem uma programação, muitas vezes trazem um pessoal bom, por exemplo, artistas, e muitas vezes eles não têm um retorno nem para pagar o artista. O pessoal anuncia que vem uma banda ou um grupo de sertanejo, aí lota, precisa ser na praça, mas se traz um outro nível, você vê que o pessoal vai fazer o show lá no (bar) Curral" (Badra, 69 anos).
\end{abstract}

Enfraquecida, observa-se um sentimento de nostalgia por algo que corre o risco de desaparecer, o que, como mostrou Gonçalves (2002) em relação aos discursos patrimoniais no Brasil, é uma das principais justificativas para nomear um

os autores denominaram "ócio". Portanto, em muitos trechos, o leitor deve considerar "lazer" e "ócio" como sinônimos.

Cad. de Pesq. Interdisc. em Ci-s. Hum-s., Florianópolis, v.12, n.101, p.199-218, ago/dez 2011 
bem como patrimônio cultural e desenvolver políticas para a sua "permanência" e "preservação".

Nessa perspectiva, o presente, assim como tudo o que é espacialmente próximo, aparecerá corroído por um processo de perda oposto àquela situação original - distante no tempo ou no espaço - definida por coerência, integridade e continuidade (GONÇALVES, 2002, p. 24).

Para parte da população, a Semana Universitária é uma das poucas possibilidades de organização juvenil para instituir formas de entretenimento, diversão e desenvolvimento para esse mesmo grupo. Dessa maneira, sua extinção não acabaria apenas com uma atividade isolada, mas atingiria a juventude santarosense. Contudo, ao analisar esses relatos, também devemos ponderar que a sua existência há mais de quatro décadas permitiu que diferentes gerações a frequentassem; e, ao falarem da relevância da semana para os mais jovens, muitos utilizam como parâmetro não o perfil e gostos dos adolescentes atuais, mas suas próprias experiências em anos ou décadas anteriores, quando ela possuía outras características. Outro ponto é que a mudança de percepção em relação à banda não é resultado somente das transformações pelas quais ela passou, mas também de uma constante reavaliação de sua importância sociocultural pelos próprios moradores. Como refletiu Cuche (1999), a construção de nossa identidade cultural é realizada de modo multidimensional e dinâmico, permitindo que o que atualmente consideramos negativo pudesse, em outro período, atender a outras necessidades e fosse valorizado.

Hoje em dia, muitos moradores acreditam que a SUSA não mais congrega os predicados que possibilitou sua classificação, na década de 1970, como movimento ou atividade cultural. Entre as justificativas dos entrevistados para essa mudança de percepção estão os estilos de música agora adotados para as apresentações e mesmo o ambiente político, que teria deixado os jovens menos engajados com as questões socioculturais. Nesta perspectiva, a concepção de cultura como "alta" cultura não mais se encaixaria no perfil do evento.

Apesar de a Semana Universitária ter começado a se enfraquecer apenas entre as décadas de 1990 a 2000, o argumento de que o clima político foi essencial para o seu sucesso é plausível. Como é sabido, foi na década de 1970, após o golpe militar de 1964, que o movimento estudantil se reorganizou no Brasil, estimulando jovens universitários a buscarem espaços de discussão e reflexão sobre os mais 
variados temas nacionais. Em contrapartida, desde os anos seguintes ao fim da ditadura militar, sua visibilidade e poder mobilizador têm diminuído. Especificamente em Santa Rosa, aquele pequeno grupo de estudantes universitários foi substituído por centenas de pessoas que têm a opção de estudar a noite em Ribeirão Preto, a maior cidade da região, e trabalhar durante o dia em Santa Rosa, mas que agora não demonstram o mesmo interesse e disponibilidade de tempo que moveu o grupo inicial. O que auxilia na sua continuidade, nos últimos anos, é a contribuição financeira que a Fundação Cultural do município oferece para que os gastos com o evento sejam pagos.

"Acho que a gente tinha que estar mais organizado, (a SUSA) tinha que ter
mais apoio da prefeitura, dos comerciantes, devia ser uma coisa mais
garantida, devia já ser maior. Porque eu peguei a SUSA dos anos 90 , e o
pessoal que pegou em 80 dizia que era melhor; os que pegaram nos 70 ,
melhor ainda, então é também a memória emotiva de quando você é muito
jovem, com 14, 15 anos. (...) Antes era mais cultural, porque tinha
repressão, ditadura, várias coisas assim. Pra passar um filme era difícil.
Passar um filme, durante a SUSA, era um máximo, ia todo mundo assistir.
Hoje não, tudo é muito liberado, você tem tudo, então não tem mais tanta
graça" (Mateus, 29 anos).

Desse modo, diferente do exemplo da Banda Sinfônica, uma ideia mais restrita de cultura fez com que a Semana Universitária perdesse prestígio entre a população. A sua defesa pelos entrevistados é feita principalmente pela sua história e continuidade e não pelo o que produz nos dias atuais. Assim sendo, torna-se ainda mais difícil a SUSA conseguir atenção da sociedade e recursos financeiros, pois não é considerada a partir do seu presente.

Entretanto, a existência de uma memória social que a considera um bem comum da população, reforçando sentimentos de pertencimento (POLLAK, 1989), permite que a SUSA seja vista como um patrimônio santa-rosense. Relembrar os acontecimentos da cidade nas últimas décadas desde 1970 passa pelo papel e transformações da Semana Universitária, pois refletiria as próprias mudanças na juventude local. Dessa forma, a SUSA se insere na memória de acontecimentos que permanecem como pontos de demarcação na história de cada geração (BOSI, 1994).

Ao mesmo tempo em que a SUSA perde espaço entre os eventos da cidade, os entrevistados desejam que ela retorne aos moldes das décadas antecedentes acreditando na sua revitalização. Porém, devido às mudanças de interesse dos jovens relatadas pelos próprios entrevistados, repetir uma fórmula anterior não é 
garantia de sucesso. Ao invés de recuperar um modelo, poderia ser mais frutífero pensar a cultura da/ na cidade a partir do que hoje interessa aos mais jovens, dos estilos musicais aos lugares de encontro. Para isto, é necessário considerar que o que atualmente se realiza na Semana Universitária faz parte da cultura juvenil e mais importante do que o tipo de atividade realizada é a abordagem e a capacidade de reflexão que ela possibilita. Se em um determinado ano verifica-se uma grande influência da música sertaneja na cidade, como observam moradores, concomitantemente às apresentações musicais poderiam ser incluídas discussões sobre a história deste estilo e a relação com a própria região onde Santa Rosa se localiza. Nesse sentido, a Semana Universitária continuaria a oferecer aquilo que atrai o público, mas utilizaria esse sucesso para levantar questionamentos, permitindo, como alguns dos entrevistados anseiam, um caráter mobilizador e mesmo, em alguns casos, político.

Verificamos, ao discutir tanto a Banda Sinfônica como a Semana Universitária com membros da população, que as pessoas desejam atividades e espaços culturais devido à ideia positiva de cultura, mas não os consideram uma opção de lazer, deixando de usufruí-los em toda a sua potencialidade. Por outro lado, desejam opções de lazer, mas não as consideram atividades culturais. Portanto, se houvesse uma relação entre cultura e lazer, a cidade ganharia nestes dois aspectos e lugares e atividades seriam mais valorizados.

Segundo Aquino e Martins (2007), a literatura sobre o lazer inclusive sugere que a sociedade seja estimulada a reconhecer os espaços de lazer e usufruí-los. $O$ mesmo pode ser dito em relação aos espaços culturais, pois ao mesmo tempo em que determinadas concepções de lazer e cultura permitem que atividades e lugares sejam bem vistos pela população, elas também podem impedir que outras manifestações sejam reconhecidas, incentivadas e financiadas, mesmo quando são consideradas importantes em algum aspecto.

\footnotetext{
"(A SUSA) não tem, realmente, uma atenção, um reconhecimento. Eu, por exemplo, nunca me interessei em dirigir uma SUSA, e quer saber?, a SUSA é um evento cultural, eu deveria ser um dos maiores interessados, mas você sabe que não vai ter a possibilidade de realmente fazer um negócio cultural. (...) Um momento desse, como a SUSA, não era para ser como um sábado à noite" (Mateus, 29 anos).

"Antes da SUSA, eu falava assim pra turma: ' - Olha, clube universitário é maior que a Semana Universitária, não pode ser só (a semana)... '. Então, como eu estava na Associação de Leitura do Brasil, chamei o presidente, o secretário, que são professores lá da Unicamp, para vir dar palestras para
} 
os professores de português. Na época, conversei com a delegada regional de educação e ela topou, juntou todos os professores da região e eles vieram dar palestras, uma de manhã e outra de tarde; eu achei super legal isso aí. Depois, durante a SUSA, amigas minhas que trabalhavam com educação especial vieram e conversaram, fizeram uma oficina com a turma da APAE. As da educação infantil vieram trabalhar com professores de educação infantil. Um amigo meu que é fotógrafo veio, deu um curso de fotografia. O bibliotecário da educação, que também era professor de dança de salão, veio e deu um curso de dança de salão. Todos os finais de tarde, no salão da SUSA, tinha dança de salão. Lotava, lotava... Foi muito legal trazer essa turma toda. (...) A comissão desse ano, praticamente, é todinha de estudantes universitários que moram em Santa Rosa e estudam a noite em Ribeirão. Me diga, como é que dá para conhecer alguma coisa cultural fazendo essa vida? Não dá. O ambiente universitário é imprescindível, e na verdade o pessoal chega, trabalha o dia inteiro, pega ônibus seis horas da tarde, desce na porta da escola sete horas, tem que entrar... (Assim) Não tem oportunidade, não tem contatos. Não é culpa deles, a SUSA foi a possível, é sempre a SUSA possível, então é legal, mantêm-se sempre. Talvez logo se ache" (Boniperti, 34 anos).

\section{CONSIDERAÇÕES FINAIS}

Através dos exemplos da Banda Sinfônica e da Semana Universitária, observa-se que a identificação de patrimônios culturais, daquilo que é memorável para a população passa pelas suas representações sociais e a invenção e produção do novo (GONDAR; DODEBEI, 2005). No nosso caso, a ideia de cultura desenvolvida pelos entrevistados permitiu que um bem fosse ainda mais reconhecido e respeitado pela população, enquanto outro luta pela sua continuidade, porque, segundo os mesmos, vem perdendo o seu caráter "cultural".

Reconhecemos que qualquer bem possui mais de um significado cultural e, assim sendo, poderíamos ter discutido outros valores atribuídos tanto a banda como a SUSA. No entanto, neste artigo, mais relevante do que apresentar todas as qualificações atribuídas aos bens vistos como os patrimônios culturais de Santa Rosa foi demonstrar como determinadas representações influenciam diretamente no papel que estes bens exercem na cidade. Se na Academia o conceito de cultura como um conjunto restrito de atividades artísticas e intelectuais é apresentado, de modo geral, como um mecanismo de discriminação, podemos verificar que os usos deste conceito pela sociedade produzem efeitos diversos, sendo em alguns aspectos até positivo. Nesse sentido, concordamos com o historiador Marc Bloch 
(2001, p. 143) quando defendeu que "uma palavra vale menos por sua etimologia do que pelo uso que dela é feito".

O que salientamos, assim como fez Clifford Geertz (2008) em sua obra, é o risco de generalizações, de buscar uma teoria social total, universal, ao contrário de, através de casos específicos, entrar em contato com uma variedade de significações que demonstram as exceções e limitações de concepções dominantes.

Seria ingênuo acreditar que o valor histórico é suficiente para legitimar um patrimônio cultural perante a sociedade, apesar da existência desta possibilidade, pois, como observou Bloch (2001), o conhecimento e as representações que produzimos sobre o passado estão em constante movimento. No nosso exemplo, a Semana Universitária Santa-rosense, apesar do seu valor memorial, vem perdendo o seu prestígio perante a população, mesmo sendo reconhecido o papel que ela exerce na cidade há mais de quarenta anos.

Assim, o que entendemos por "mundo real" nada mais é do que o fruto dos nossos sentidos, sentimentos e capacidade de imaginar (PESAVENTO, 2007), o que contribui para apontarmos os diferentes usos de determinadas noções, como de cultura, na construção do nosso passado, até porque "ao inventar o passado, contando a história de suas origens e de seu percurso no tempo para explicar seu presente, a cidade constrói seu futuro" (PESAVENTO, 2007, p. 17). 


\section{REFERÊNCIAS}

AQUINO, C. A. B.; MARTINS, J. C. de O. Ócio, lazer e tempo livre na sociedade do consumo e do trabalho. Revista Mal-estar e Subjetividade, Fortaleza, v. 7, n. 2, p. 479-500, set. 2007. Disponível em: http://www.unifor.br/notitia/file/1851.pdf. Acesso em 12 jan. 2010.

ARANTES, A. A. (Org.). Produzindo o passado: estratégias de construção do patrimônio cultural. São Paulo: Brasiliense, 1984.

$\mathrm{BLOCH}, \mathrm{M}$. Apologia da história ou $\mathrm{O}$ ofício do historiador. Tradução André Telles. Prefácio Jacques Le Goff. Rio de Janeiro: Jorge Zahar Ed., 2001.

BOSI, E. Memória e sociedade: lembrança de velhos. São Paulo: Companhia das Letras, 1994.

BRASIL. Constituição Federal (1988). Disponível em:

http://www.planalto.gov.br/ccivil_03/constituicao/constitui\%C3\%A7ao.htm. Acesso em: 28 ago. 2008.

CHARTIER, R. A história ou a leitura do tempo. Tradução Cristina Antunes. Belo Horizonte: Autêntica Editora, 2009.

CUCHE, D. A noção de cultura nas ciências sociais. Tradução Viviane Ribeiro. Bauru: EDUSC, 1999.

DAMATTA, R. Você tem cultura? Jornal da Embratel, Rio de Janeiro, 1981.

Disponível em: http://www.furb.br/2005/arquivos/788660-

650601/voce\%20tem\%20cultura.pdf. Acesso em: 08 jan. 2010.

DUMAZEDIER, J. Lazer e cultura popular. Tradução Maria de Lourdes Santos Machado. 3. ed. São Paulo: Perspectiva, 2001.

DURHAM, E. R. Cultura, patrimônio e preservação (Texto II). In: ARANTES, A. A. (Org.). Produzindo o passado: estratégias de construção do patrimônio cultural. São Paulo: Brasiliense, 1984.

FONSECA, M. C. L. O patrimônio em processo: trajetória da política federal de preservação no Brasil. 2. ed. rev. e ampl. Rio de Janeiro: Editora UFRJ; MinC IPHAN, 2005.

GARCÍA CANCLINI, N. Diferentes, desiguais e desconectados: mapas de interculturalidade. Tradução Luiz Sérgio Henriques. 2. ed. Rio de Janeiro: Editora UFRJ, 2007.

GEERTZ, C. A interpretação das culturas. Rio de Janeiro: LTC, 2008.

GONÇALVES, J. R. S. A retórica da perda: os discursos do patrimônio cultural no Brasil. 2. ed. Rio de Janeiro: Editora UFRJ; IPHAN, 2002. 
GONÇALVES, J. R. S. Antropologia dos objetos: coleções, museus e patrimônios. Rio de Janeiro: IPHAN, 2007.

GONDAR, J.; DODEBEI, V. (Orgs.). O que é memória social? Rio de Janeiro: Contra Capa, 2005.

HOBSBAWN, E.; RANGER, T. (Orgs.). A invenção das tradições. Tradução Celina Cardim Cavalcante. 5. ed. São Paulo: Paz e Terra, 2008.

LARAIA, R. de B. Cultura: um conceito antropológico. 14. ed. Rio de Janeiro: Jorge Zahar Ed., 2001.

MEIHY, J. C. S. B.; HOLANDA, F. História oral: como fazer, como pensar. São Paulo: Contexto, 2007.

PESAVENTO, S. J. Cidades visíveis, cidades sensíveis, cidades imaginárias. Revista Brasileira de História, São Paulo, v. 27, n. 53, p. 11-23, 2007. Disponível em: http://www.scielo.br/pdf/rbh/v27n53/a02v5327.pdf. Acesso em 14 jan. 2010.

POLLAK, M. Memória, esquecimento, silêncio. Estudos Históricos, tradução Dora Rocha Flaksman, Rio de Janeiro, v. 2, n. 3, p. 3-15, 1989. Disponível em: http://www2.uel.br/cch/cdph/arqtxt/Memoria_esquecimento_silencio.pdf. Acesso em 30 dez. 2009.

PORTELLI, A. A Filosofia e os fatos: narração, interpretação e significado nas memórias e nas fontes orais. Tempo, tradução Ingeborg K. de Mendonça e Carlos Espejo Muriel, Rio de Janeiro, v. 1, n. 2, p. 59-72, 1996. Disponível em:

<http://www.historia.uff.br/tempo/artigos_dossie/artg2-3.pdf>. Acesso em: 1 jul. 2009.

ROUVEROL, A. J. Collaborative oral history in a correctional setting: promise and pitfalls. The Oral History Review, Berkeley, v. 30, n. 1, p. 61-85, 2003. Disponível em: <http://ohr.oxfordjournals.org/cgi/reprint/30/1/61.pdf>. Acesso em: 02 jul. 2010.

SANTA ROSA DE VITERBO. Banda Sinfônica. Um grande salto via Lei Roaunet. c2009. Disponível em: http://www.bandasinfonicasrv.com/historico-5.php. Acesso em: 11 jan. 2010.

WILLIAMS, R. Cultura. Tradução Lólio Lourenço de Oliveira. 3. ed. São Paulo: Paz e Terra, 2008.

WILLIAMS, R. Palavras-chave: um vocabulário de cultura e sociedade. Tradução Sandra Guardini Vasconcelos. Prefácio Maria Elisa Cevasco. São Paulo: Boitempo Editorial, 2007.

Artigo:

Recebido em: 11/05/2011

Aceito em: 20/09/2011 